\title{
Derecho comunitario europeo sobre la publicidad y su transposición al derecho español*
}

\author{
Juan Carlos Martínez-Salcedo* \\ Recibido: mayo de 2015 \\ Evaluado: agosto de 2015 \\ Aprobado: noviembre de 2015
}

\section{RESUMEN}

La publicidad comercial es la principal herramienta de marketing de bienes y servicios con que cuentan los empresarios en el mercado, por el fácil acceso al destinatario y su capacidad para influenciar su decisión de compra. Las normas sobre publicidad colindan directamente con las disposiciones sobre competencia desleal. Por tal razón, la Unión Europea, consciente de su importancia para el desarrollo del mercado interior, ha estructurado un conjunto de normas que regulan la publicidad comercial, y que buscan erradicar los anuncios que conlleven actos desleales que alteren irregularmente el mercado, afectando indistintamente a competidores y consumidores. España debía transponer al derecho nacional las disposiciones normativas comunitarias, exigencia que, para ser cumplida, implicó modificaciones sustanciales y complejas al régimen publicitario preexistente.

Palabras clave: publicidad, competencia desleal, publicidad engañosa, publicidad agresiva, publicidad desleal, consumidor o usuario.

\footnotetext{
Este documento hace parte de la etapa preliminar de la investigación doctoral del autor, inscrita dentro de la línea de investigación "Internet, Comercio Electrónico, Telecomunicaciones e Informática", del Grupo de Estudios en Internet, Comercio Electrónico, Telecomunicaciones e Informática (GECTI) de la Facultad de Derecho de la Universidad de Los Andes.

** Abogado admitido en Colombia y España, egresado de la Universidad de La Sabana (Colombia), especialista en Derecho Contractual por la Universidad del Rosario (Colombia) y magíster en Derecho Privado por la Universidad Carlos III de Madrid (España). Profesor y candidato a doctor en Derecho, Facultad de Derecho de la Universidad de Los Andes. jc.martinez12@uniandes.edu.co.
} 


\title{
European Community Law on Advertising and Its Transposition to the Spanish Law
}

\begin{abstract}
Commercial advertising is the main tool for marketing goods and services offered by businessmen in the market due to the easy access to final customers and its capacity to influence their purchase decisions. Norms on advertising are directly related to those on unfair competition. For this reason, the European Union, aware of its importance for the development of internal market, has created a number of norms to regulate commercial advertising and to eradicate all ads that may imply unfair actions that can irregularly alter the market and indiscriminately affect competitors and consumers. Spain was required to transpose community regulatory provisions to its national law; compliance with this requirement involved significant and complex modifications of the existing advertising system.
\end{abstract}

Key words: Advertising; unfair competition; misleading advertising; aggressive advertising; unfair advertising; consumer or user. 


\section{INTRODUCCIÓN}

La publicidad es un instrumento de marketing que se ha consolidado como el principal medio de información precontractual; los empresarios acuden al mensaje publicitario para incentivar la adquisición de los bienes o servicios por ellos ofrecidos, favorecidos por la facilidad de transmisión del mensaje al receptor y su aptitud para determinar sus conductas económicas (Pérez, 1990, p. 197). Aunque la forma de hacer publicidad es diversa, polivalente y adaptable a cada realidad social, y al destinatario mismo, el fin perseguido por el anunciante no varía: lograr la atención de un consumidor o usuario con el propósito de influir en la decisión de compra de un bien o servicio (Rodríguez, 1999, p. 171).

La importancia económica que tiene el mensaje publicitario exige tener precisión respecto a los límites legales dentro de los cuales el anunciante debe maniobrar, para así no afectar los intereses protegibles de competidores y consumidores. Con la finalidad de establecer estos límites, en primer lugar, debemos estudiar qué entendemos por publicidad, para luego sí precisar el sentido, alcance y forma en que las normas sobre esta materia tienen injerencia sobre el derecho que le asiste al empresario para publicitar sus productos y servicios en el mercado.

Por tal razón, es pertinente determinar cuáles fueron las modificaciones que ha tenido que acoger España, con ocasión de la trasposición al derecho nacional de las normas comunitarias proferidas por la Unión Europea (en adelante, UE) para atender los nuevos retos que la publicidad comercial ha traído consigo, a partir de los nuevos escenarios por los que puede ser puesta a disposición de los consumidores.

Para ello, fue pertinente revisar los antecedentes regulatorios sobre la publicidad comercial, tanto en el ámbito del derecho comunitario europeo, como en el derecho español; luego de esto, se estableció el estado actual de la cuestión, identificando aquellos aspectos normativos que fueron recientemente incorporados en el nivel comunitario, que exigían su transposición al derecho nacional; finalmente, fue necesario contrastar el alcance de dicha trasposición al derecho español, para detenernos en algunos aspectos que revisten especial importancia, bien por las tensiones que causaron con el derecho preexistente o, bien, por la novedad de las mismas.

Así las cosas, primero será necesario establecer qué es publicidad comercial, y qué no, para luego mostrar al lector los antecedentes regulatorios sobre esta materia en el derecho comunitario europeo y español. Posteriormente, es pertinente estudiar las interacciones entre la competencia desleal y el derecho de la publicidad comercial, para identificar algunas tensiones normativas que se presentan en el derecho, tanto comunitario como español. Luego estudiaremos el alcance de la regulación de la publicidad como acto de competencia desleal, así como también algunas particularidades de importancia, que nos permitirán definir el alcance de la trasposición de las normas 
comunitarias sobre publicidad comercial al derecho español.

\section{1. ¿QUÉ ES LA PUBLICIDAD?}

Al acudir al Diccionario de la Real Academia Española para conocer el significado del término publicidad, se observa que las acepciones primera y segunda lo definen respectivamente como "cualidad o estado de público" y "conjunto de medios que se emplean para divulgar o extender la noticia de las cosas o de los hechos", mientras que la acepción tercera lo hace como "3. f. divulgación de noticias o anuncios de carácter comercial para atraer a posibles compradores, espectadores, usuarios, etc." (Real Academia Española, 2001).

Estas definiciones de publicidad descomponen el término en dos sentidos: uno amplio, el hacer público algo; y uno reducido, la publicidad como fenómeno social (De la Cuesta, 2002, p. 25).

\subsection{La publicidad en sentido amplio}

La cualidad de "hacer público" que conlleva el término publicidad lo hace funcionalmente polivalente en el entorno jurídico, pues puede hacer referencia a diferentes instituciones que, per se, no se relacionan, pero que sí cumplen con una labor propia según el ámbito al cual correspondan: la publicidad de las normas, la publicidad registral, la publicidad de los títulos valores, los hechos notorios, entre otros (Santaella, 2003, p. 23). La función de divulgación al público que cumple el sentido amplio del término escapa al objeto del derecho de la publicidad en razón a que su concreción es producto de un deber o de una obligación legal (López, 2004, p. 40). Por ello, la publicidad definida en esta acepción no será objeto de estudio en este artículo, cuyo límite estará demarcado por la publicidad como actividad comercial.

\subsection{Publicidad en sentido estricto - mensaje publicitario y publicidad comercial-}

Esta acepción hace referencia a un concepto genérico de mensaje publicitario, catalogándolo como "un método para comunicar a muchas personas el mensaje de un patrocinador a través de un medio impersonal" (Benavides, 1997, p. 186). El mensaje publicitario incorpora dentro de sus especies la publicidad comercial (Rozados, 2009, p. 25), caracterizada por la confluencia simultánea de dos elementos, uno objetivo y otro subjetivo.

(i) Elemento objetivo. Constituido por el contenido del mensaje informativo y su forma de presentación al receptor, cuya determinación dependerá de aquellos que han intervenido en el proceso comunicativo (anunciantes, agencias y medios de publicidad (Rozados, 2009, p. 13).

(ii) Elemento subjetivo. Constituido por el carácter persuasivo del mensaje (López, 2004, p. 51). El mensaje publicitario se concibe como una entidad de comunicación para ser usada en una situación comunicativa de interacción entre emisor y destinatario, con el propósito de ejercer sobre este último una influencia di- 
recta, capaz de provocar variaciones en su comportamiento (Peña, 2007, p. 51).

El elemento subjetivo cobra importancia por ser al que se acude para determinar si se trata de un mensaje publicitario con presencia o no de contenido comercial. Cuando este es iniciado por órganos públicos en desarrollo de sus funciones (Souvirón, 1999, p. 461)', o por sujetos privados en ejercicio de actividades no comerciales o sin la intención promocional de productos o servicios puestos en el comercio, se considera que el anuncio carece de contenido comercial (Souvirón, 1999, p. 461), aun cuando su propósito sea influenciar las decisiones del destinatario final, tal y como ocurre con la publicidad política o la publicidad institucional.

A contrario sensu, será considerado como mensaje publicitario con contenido comercial -publicidad comercial-, aquel cuyo emisor está actuando por voluntad propia y no en ejercicio de un deber jurídico, con la intención de promover la adquisición de bienes y servicios. En este caso, el anuncio publicitario es "creado por y para un tipo de actividad social y económica con el fin de persuadir a los posibles consumidores, mediante un proceso de argumentación" (Peña, 2007, p. 36).

\footnotetext{
El autor expone que "para este tipo de publicidad cuando es realizada por órganos públicos se utiliza el término de publicidad institucional, entendiendo por tal la publicidad no gratuita promovida por el Estado o Administraciones públicas y contratada con los medios de comunicación social" (Souvirón, 1999, p. 461).
}

\subsection{Concepto normativo de la publicidad comercial}

En la UE, el artículo 2 literal a) de la Directiva 2006/114/CE, de 12 de diciembre de 2006, del Parlamento Europeo y del Consejo, sobre publicidad engañosa y publicidad comparativa (en adelante, Directiva 2006/114/CE), define la publicidad como:

\begin{abstract}
Toda forma de comunicación realizada en el marco de una actividad comercial, industrial, artesanal o liberal con el fin de promover el suministro de bienes o la prestación de servicios, incluidos los bienes inmuebles, los derechos y las obligaciones (Unión Europea, 2006).
\end{abstract}

España acoge, en el artículo 2 de la Ley 34/1988, de 11 de noviembre, Ley General de Publicidad (en adelante, LGP), el concepto antes referido, al cual adiciona algunas menciones que ayudan a precisar su ámbito de aplicación:
Toda forma de comunicación realizada por una persona física o jurídica, pública o privada, en el ejercicio de una actividad com- ercial, industrial, artesanal o pro- fesional, con el fin de promover de forma directa o indirecta la contratación de bienes muebles o inmuebles, servicios, derechos y obligaciones (España, 1988) (Subrayado del autor).

La definición normativa de la directiva comunitaria está restringida a solo una variante de publicidad: la publicidad comercial (Santaella, 1989, p. 57). Por tanto, 
se trata de una definición restrictiva "a efectos" de dicha norma, que impide la posibilidad de ser aplicada extensivamente a otros supuestos como el de la publicidad institucional (Higueras, 1998, p. 35).

Así también ocurre en el derecho español; la LGP ha reconocido la existencia de otras actividades publicitarias excluidas de su ámbito de aplicación, como se infiere del tenor literal del artículo 7, en el que se establece que "Lo dispuesto en el mismo -en el Título III- será de aplicación a todos los contratos publicitarios, aun cuando versen sobre actividades publicitarias no comprendidas en el artículo 2" (España, 1988).

\section{ANTECEDENTES REGULATORIOS DE LA PUBLICIDAD COMERCIAL}

La publicidad, como práctica comercial que es, ha sido objeto de regulación tanto en la UE como en sus Estados miembros. Las normas en esta materia están afectadas por una tendencia de continua modificación, desencadenada, entre otras razones, por los retos que representan las nuevas tecnologías, los medios de comunicación y los entornos virtuales, dentro de las que se destacan las que se estudian a continuación.

\subsection{Antecedentes normativos en la Unión Europea}

Para lograr el correcto funcionamiento de la UE se requiere cierta compatibilidad estructural y jurídica entre los Estados miembros. Por tanto, es necesario que ocurran algunas intervenciones desde el seno de la Unión sobre aquellos asuntos en los que existan disparidades normativas con el propósito de armonizar las legislaciones nacionales. En torno a la publicidad, la UE consideró que este es un fenómeno que traspasa las fronteras, incluso de sus asociados, y que puede tener injerencia directa sobre el establecimiento y funcionamiento del mercado común, por lo que es necesario promulgar algunas normas que puedan prevenir disfuncionalidades.

La primera disposición normativa sobre este asunto fue dictada por el Consejo, que aprobó la Directiva 84/450/CEE, de 10 de septiembre de 1984, relativa a la aproximación de las disposiciones legales, reglamentarias y administrativas de los Estados miembros en materia de publicidad engañosa (en adelante, Directiva 84/450/CEE). El objeto primordial de esta Directiva era la protección de los consumidores, de los empresarios y del interés general frente a la publicidad engañosa y sus consecuencias desleales (Unión Europea, 1984).

Con posterioridad se profirió la Directiva 97/55/CE del Parlamento Europeo y del Consejo de 6 de octubre de 1997 por la que se modifica la Directiva 84/450/CEE sobre publicidad engañosa, a fin de incluir en la misma la publicidad comparativa (en adelante, Directiva 97/55/CE), la cual se constituyó en el eje básico de regulación del derecho comunitario de competencia desleal (Unión Europea, 1997).

En el año 2001, se expide el Libro Verde sobre la protección de los consumidores 
en la UE, en el que se plantea la necesidad de establecer una directiva marco sobre prácticas comerciales entre empresas y consumidores (Comisión de la Unión Europea, 2001). En desarrollo de los objetivos del Libro Verde se promulga la Directiva 2005/29/CE, relativa a las prácticas comerciales en sus relaciones con los consumidores en el mercado interior (en adelante, Directiva 2005/29/CE), cuyo ámbito de aplicación se restringe a las prácticas desleales de las empresas que afectan los intereses económicos de los consumidores (Unión Europea, 2005).

La Directiva 84/450/CEE fue modificada en repetidas ocasiones de forma sustancial y poco homogénea, por lo que el legislador europeo consideró necesario armonizar la normativa comunitaria relativa a la publicidad, para cuyo propósito promulgó la Directiva 2006/114/CE, de 12 de diciembre de 2006, del Parlamento Europeo y del Consejo, sobre publicidad engañosa y la publicidad comparativa, cuya vigencia aún hoy se mantiene (Unión Europea, 2006).

\subsection{Antecedentes normativos en España}

La actividad publicitaria en España fue objeto de regulación, por primera vez, por la Ley 61/1964, de 11 de junio, por la que se aprueba el Estatuto de la Publicidad (en adelante EP). La tipificación de estas normas estuvo influida por los cambios que, hacia la década del 60, alteraron las estructuras económicas nacionales entre los que cobraba especial importancia la publicidad como medio de difusión de bienes y/o servicios, al punto de ser una vía adecuada para lograr el prestigio de las marcas, nombres y denominaciones comerciales en el mercado (España, 1964)².

El EP fue sustituido por la LGP, en cuya exposición de motivos se recogen las causas que desencadenaron su aparición, entre otras, destacándose la rigidez normativa del EP -que lo hicieron arcaico y anacrónico para la regulación de la actividad publicitaria-, la promulgación de la Constitución Española de 1978 que desencadenó la institucionalidad de algunos preceptos normativos, y, quizá la más importante, la adhesión de España a la entonces Comunidades Europeas (España, 1985), que implicó, entre otros compromisos, el actualizar y/o armonizar su legislación interna a la normativa comunitaria en aquellos asuntos en que resultare necesario. Para ese momento, el Consejo de la UE ya había aprobado la Directiva 84/450/CEE, que debía ser transpuesta al ordenamiento jurídico español.

La LGP fue, durante algún tiempo, norma exclusiva en lo concerniente a la regulación de la publicidad; no obstante, algunos supuestos fácticos de la realidad comercial escapaban de su ámbito de aplicación. Consciente de ello, el legislador español, en la Ley 3/1991 de 10 de enero, de Competencia Desleal (en adelante LCD), incorpora como conduc-

\footnotetext{
Así lo expresó el legislador español en la Exposición de Motivos, para quien "la publicidad se ha ido convirtiendo en una realidad social que ocupa hoy un rango eminente no sólo dentro del marco de cada una de las empresas interesadas, donde moviliza ingentes cantidades de dinero y extraordinarias energías humanas, sino también y, sobre todo, en el marco, más amplio, de la vida nacional" (España, 1964).
} 
tas reprochables, aspectos relativos a la publicidad comparativa y a los actos de imitación, que llegan para coexistir con las ya tipificadas en la LGP (España, 1991). Si bien lo pretendido por el legislador era el establecimiento de un régimen de publicidad completo e integral, lo que se consiguió fue la creación de un concurso normativo entre la LGP y la LCD en lo concerniente a ciertas conductas reprochables tales como los actos de denigración y descrédito, así como también en el procedimiento por seguir para lograr el cese de las mismas (Lara, 2011, p. 115)

La expedición en la UE de la Directiva 97/55/CE produjo una modificación del régimen publicitario que se realizó mediante Ley 39/2002, de 28 de octubre, de transposición al ordenamiento jurídico español de diversas directivas relativas a la protección de los intereses de los consumidores y usuarios (España, 2002). Ello supuso una reforma parcial de la LGP para admitir la publicidad comparativa y enunciar las condiciones que se debían observar para que sea considerada lícita, así como también lo concerniente a la acción colectiva de cesación en materia de publicidad ilícita.

\footnotetext{
3 Al respecto, el autor expone que "la LGP no exigía en cuanto al acto realizado a través de una manifestación publicitaria que el contenido de ésta fuera falso; esto es, aunque la alegación publicitaria fuera veraz, si es así que sirve para desacreditar o menospreciar a una persona o a sus productos o servicios, la misma merecía el calificativo de publicidad desleal. Sin embargo, la LCD admite la exceptio veritatis (...) la LGP exigía para que existiese denigración que ésta fuera efectiva, mientras que en la LCD basta la susceptibilidad de menoscabar el crédito de un operador económico para que se considere la existencia de denigración" (Lara, 2011, p. 115).
}

La más reciente modificación a la LGP es llevada a cabo por la Ley 29/2009, de 30 de diciembre, por la que se modifica el régimen legal de la competencia desleal y de la publicidad para la mejora de la protección de los consumidores y usuarios, con el objeto de incorporar al derecho español las directivas 2005/29/CE y 2006/114/CE de la UE. Esta Ley, en primer lugar, rompe el concurso normativo existente entre la LGP y la LCD, antes mencionado, toda vez que, en primer lugar, deroga el Título IV LGP sobre el régimen de acciones, debiendo entonces acudirse a lo establecido en la LCD para los actos de competencia desleal cuando se esté ante supuestos de publicad ilícita (España, 2009).

En segundo lugar, la LGP cede la tipificación expresa de la publicidad engañosa y de la publicidad desleal en favor de la LCD. Si bien el modificado artículo 3 LGP sigue incluyendo estos supuestos como modalidades de publicidad ilícita, la redacción actual no entra a definirlas, sino que se limita a remitirse a lo dispuesto en la LCD, evitando así una doble tipificación (Tato, 2010, p. 142).

\section{LA RELACIÓN ENTRE PUBLICIDAD COMERCIAL $Y$ YLL DERECHO DE LA COMPETENCIA DESLEAL}

Las prácticas concurrenciales están reglamentadas por el derecho de la competencia con el propósito de proteger los intereses de todos aquellos que confluyen en el mercado -los consumidores y los competidores-. El primer componente del derecho de la competencia es su defensa; por tanto, sus normas tienen como 
propósito garantizar la eficiencia del mercado prohibiendo las prácticas colusorias, el abuso de la posición dominante y el falseamiento de la libre competencia (España, 2007).

El segundo componente es la competencia desleal, cuyas normas jurídicas están dirigidas a erradicar del mercado las conductas desleales que perturban el correcto funcionamiento del tráfico económico. Es por esto que es admisible considerar al derecho de la competencia desleal como el "derecho ordenador de las relaciones de mercado" (Menéndez \& Rojo, 2013, p. 28), y en consecuencia, como el encargado de establecer la prohibición de las prácticas comerciales desleales.

Para que estas prácticas sean reprochadas deben cumplirse tres condiciones: i) que sea realizada en el mercado, esto es, que se trate de un acto dotado de trascendencia externa, ii) que se lleve a cabo con fines concurrenciales, es decir, que el acto tenga por finalidad promover o asegurar la difusión en el mercado de las prestaciones propias o de un tercero, y iii) que sea desleal. Si dichas circunstancias están presentes, la conducta podrá ser perseguida como tal.

La publicidad comercial es una práctica susceptible de examinarse bajo las normas del derecho de la competencia desleal. Se trata de una actividad dotada de transcendencia externa, a la que acuden los empresarios para informar a los consumidores o usuarios de los productos y servicios que ofrecen. Esta labor de difusión esta siempre sometida a la riva- lidad comercial con otros oferentes que también actúan bajo las reglas de la libre competencia, por lo que se ha de exigir el apego a las prácticas leales. No obstante, en el día a día se identifican anuncios que rompen con la debida lealtad y que falsean la competencia, desencadenando una afectación directa sobre los competidores y los consumidores, que dan lugar al reproche por deslealtad competencial.

\subsection{Tratamiento jurídico de la publicidad comercial en el derecho comunitario europeo}

Debido a la importancia adquirida por la publicidad como actividad comercial, así como también al reconocimiento de las relaciones jurídicas asimétricas entre productores y expendedores con consumidores y usuarios, la UE se ha visto abocada a implementar modificaciones normativas sobre esta materia (Tribunal Constitucional de España, Sentencia del 26 de enero de 1989) ${ }^{4}$. Para ello, el legislador comunitario ha proferido algunas directivas dirigidas a los Estados miembros, quienes deben transponerla a sus derechos nacionales (Bacigalupo, Fuentetaja, \& Linde, 2012, p. 437).

Le corresponde al legislador nacional incorporar al derecho interno, mediante un acto de transposición, los contenidos

\footnotetext{
Esta sentencia, en el fundamento segundo, expone que cuando "la defensa de los consumidores y usuarios se configura como un principio general informador del ordenamiento jurídico, no está en efecto, sino reiterando, en otros términos, que esa defensa, constitucionalmente garantizada informará la legislación positiva, la práctica judicial y la actuación de los poderes públicos" (Tribunal Constitucional de España, Sentencia del 26 de enero de 1989).
} 
normativos determinados en los objetivos de la directiva, que es a lo único a lo que están vinculados en exclusiva, otorgando a cada Estado un margen de actuación en la transposición que le permita amoldar la exigencia comunitaria a las particularidades nacionales respectivas.

En la UE, la Directiva 2005/29/CE contiene los preceptos básicos que en materia de protección de los consumidores y usuarios han de seguir los Estados miembros en aras de la armonización y homogeneización del derecho nacional. Esta norma tiene como novedad la incorporación de ciertas prácticas comerciales que deben ser consideradas desleales y que, por tanto, han de estar prohibidas, puesto que se presume que si estuviesen permitidas perjudicarían los intereses económicos de los consumidores o usuarios.

El legislador europeo identifica el mensaje publicitario como una vertiente más de las prácticas comerciales a las que acude el empresario para informar al destinatario de la existencia y características de un producto o servicio. Así lo ha plasmado en el artículo 2.b de la Directiva 2005/29/ $\mathrm{CE}$ que define las prácticas comerciales de las empresas en sus relaciones con los consumidores o usuarios como: "Todo acto, omisión, conducta o manifestación, o comunicación comercial, incluidas la publicidad y la comercialización, procedente de un comerciante y directamente relacionado con la promoción, la venta o el suministro de un producto a los consumidores" (Unión Europea, 2005) (Subrayado del autor).
En la definición anterior el legislador europeo enfatiza en la relación empresarioconsumidor. Esta relación encuentra una explicación en el artículo 3 ibídem referente al ámbito de aplicación. Su determinación está fijada por el sujeto pasivo de la conducta desleal, siendo solamente aplicable cuando el afectado es un consumidor o usuario, pero no en aquellos supuestos en los que el afectado es otro empresario (Unión Europea, 2005).

Ahora bien, cuando la práctica comercial está configurada a partir de un mensaje publicitario ilícito que afecta a un no consumidor, la norma comunitaria que resulta aplicable será la Directiva 2006/114/CE. Esta última no contiene una referencia específica respecto de la publicidad como práctica comercial; sin embargo, cuando se ocupa de definir qué ha de entenderse por publicidad, establece como marco de referencia las comunicaciones realizadas en el desarrollo de una actividad comercial que tiene por objeto la promoción de los bienes, servicios, derechos, y obligaciones (Unión Europea, 2006) ${ }^{6}$.

Respecto a la caracterización de las prácticas comerciales desleales, la Directiva 2005/29/CE -artículo 5- tiene

\footnotetext{
Artículo 3.1. "La presente Directiva será aplicable a las prácticas comerciales desleales de las empresas en sus relaciones con los consumidores según establece el artículo 5, antes, durante y después de una transacción comercial en relación con un producto".

6 Artículo 2.a "A efectos de la presente Directiva, se entenderá por: a) «consumidor»: cualquier persona física que, en las prácticas comerciales contempladas por la presente Directiva, actúe con un propósito ajeno a su actividad económica, negocio, oficio o profesión"
} 
como punto de partida una prohibición general, en la que están recogidas las no mencionadas taxativamente, sean conocidas o no -como herramienta de vigencia prospectiva-, para, subsiguientemente, incorporar disposiciones que abarcan supuestos fácticos específicos, tendentes a prevenir la explotación de los consumidores o usuarios vulnerables (Unión Europea, 2005).

En cambio, la Directiva 2006/114/CE, más que enunciar supuestos fácticos reprochables, lo que hace es informar qué ha de entenderse por publicidad engañosa y publicidad comparativa, para luego estipular los aspectos que se han de tener en cuenta para establecer si el contenido de la publicidad puede dar lugar a un reproche de ilicitud de acuerdo con lo preceptuado. Esta Directiva tambien excluye de su ámbito de aplicación la protección de los consumidores, señalando expresamente que su objeto es salvaguardar a los comerciantes de prácticas reprochables derivadas de la publicidad engañosa, al mismo tiempo que establece los requisitos que ha de cumplir la publicidad comparativa para que sea considerada lícita (Unión Europea, 2006) ${ }^{7}$.

En consecuencia, la publicidad comercial como práctica desleal encuentra una doble regulación, sin incurrir por ello en un concurso normativo, determinada por las directivas 2005/29/CE y 2006/114/CE, en cuyo articulado están presentes los

7 Artículo 1. "La presente Directiva tiene por objeto proteger a los comerciantes contra la publicidad engañosa y sus consecuencias injustas y establecer las condiciones en las que estará permitida la publicidad comparativa" (Unión Europea, 2006). lineamentos para su correcta aplicación, sin sobreponerse entre sí (Fernández, Herrera, E Tato, 2010, p. 35).

\subsection{Tratamiento jurídico de la publicidad comercial en el derecho español}

La LCD tipifica la publicidad ilícita como acto de competencia desleal, pero no define cuáles son las modalidades ni los elementos que dan lugar al ilícito concurrencial. Para concretar estas modalidades, debemos acudir a la remisión que hace el artículo 18 LCD a la LGP: "La publicidad considerada ilícita por la Ley General de Publicidad, se reputará desleal" (España, 1991).

La remisión a la LGP está dirigida al artículo 3, en el que se mencionan las modalidades de publicidad ilícita. De estas, debemos centrarnos en las conductas reprochables referidas en el literal e), cuya concreción requiere una necesaria devolución a la LCD para buscar en sus líneas lo que ha de considerarse como acción constitutiva de un ilícito concurrencial (España, 1988).

El alcance de esta remisión es muy difuso, dado que la regulación para este tipo de conductas está contenida a lo largo de la LCD. La publicidad engañosa es abordada por los artículos 5, 7 y 21 a 27; la publicidad agresiva se documenta en los artículos 8, y 28 a 31; mientras que la publicidad desleal propiamente dicha, está contenida en los artículos 4, 6, 9, 10, 12, y 20 bajo las modalidades de publicidad confusionista, denigratoria, comparativa, de uso inadecuado de signos distintivos 
y contraria a la buena fe y buenos usos mercantiles (Tato, 2010, p. 151).

Es pertinente resaltar que, a pesar de la fragmentación en atención al sujeto pasivo que presenta la UE en la regulación de la publicidad como práctica comercial desleal, en España la LCD abarca la protección de los consumidores y usuarios, así como también la de otros competidores, aunque en su articulado sí existe una clara diferenciación.

\section{TRATAMIENTO JURIDICO DE LA PUBLICIDAD DESLEAL}

La reprochabilidad del mensaje publicitario ilícito está determinada por el carácter engañoso, agresivo o desleal propiamente dicho que puede revestir un mensaje publicitario frente al consumidor o usuario.

Los criterios de evaluación de ilicitud están determinados por la noción de consumidor medio, cuyo concepto no fue abordado por el legislador. Por tanto, corresponde a los tribunales determinar lo que se ha de entender por tal. Al respecto, el TJUE ${ }^{8}$, en una interpretación prejudicial solicitada por el Marknadsdomstolen ${ }^{9}$ sobre algunos artículos de esta Directiva, ha manifestado que para definir el carácter engañoso de una publicidad "los tribunales nacionales deben tomar en considera-

8 TJUE. Sentencia del 12 de mayo de 2011. Konsumentombudsmannen contra Ving Sverige AB. Petición de decisión prejudicial: Marknadsdomstolen Suecia. Asunto C-122/10 (TJUE, Sentencia del 12 de mayo de 2011, 2011).

9 Tribunal de Competencia y Mercado del Reino de Suecia. ción la percepción del consumidor medio, aquel que está normalmente informado y es razonablemente atento y perspicaz, teniendo en cuenta los factores sociales, culturales y lingüísticos" (TJUE, Sentencia del 12 de mayo de 2011, 2011).

Estos criterios deberán ser usados por los tribunales en cada caso en particular, quienes deberán tener en consideración otros factores, tales como la claridad de la información aportada a los consumidores o el riesgo de error en relación con el grupo de consumidores al que la publicidad se dirige (Vilajoana, 2011, p. 45), si se trata de grupos especialmente vulnerables -bien por su edad, por presentar discapacidad, por tener afectada su capacidad de compresión, o por su credibilidad-, en cuyos casos los criterios para determinar al consumidor medio se incrementaran en proporción a los efectos y expectativas que pueda generar sobre ese destinatario, erradicado así la posibilidad de que se aplique un criterio estadístico (Fernández et al., 2010, p. 113).

\subsection{La publicidad engañosa}

La publicidad engañosa es una práctica desleal cuya afectación recae directamente sobre los intereses económicos del consumidor con consecuencias indirectas sobre los competidores que operan legítimamente. Esta doble afectación fue tenida en cuenta por el legislador comunitario, quien incorporó disposiciones normativas sobre esta materia tanto en la Directiva 2005/29/CE, que incluye a la publicidad engañosa como una expresión de las prácticas desleales, como en la Di- 
rectiva 2006/114/CE sobre dicha materia en particular. Por tal razón, estudiamos la publicidad engañosa a partir de los supuestos tipificados en la Directiva 2006/114/CE, sin dejar de remitirnos a la Directiva 2005/29/CE para abordar aspectos relevantes que aquí se tratan y que complementan su regulación.

Concepto. El artículo 2.b de la Directiva 2006/114/CE establece que la publicidad engañosa es:

Toda publicidad que, de una manera cualquiera, incluida su presentación, induce a error o puede inducir a error a las personas a las que se dirige o afecta y que, debido a su carácter engañoso, puede afectar su comportamiento económico o que, por estas razones, perjudica o es capaz de perjudicar a un competidor (Unión Europea, 2006).

En el ámbito del derecho español, el legislador no suministra, ni en la LCD ni en la LGP, definición explícita alguna de publicidad engañosa; sin embargo, dado que la publicidad es una práctica comercial, se debe acudir a los artículos 5 y 7 LCD en los que se tachan como práctica desleal, por acción u omisión, aquellos anuncios que induzcan o puedan inducir a error a los destinatarios, siendo susceptibles de alterar su comportamiento económico (Tato, 2010, p. 294).

Es pertinente indicar que, si bien en la Directiva 2005/29/CE y en la LCD existe un catálogo o lista negra de prácticas reprochables que solo son aplicables frente a consumidores o usuarios, en el caso de la publicidad engañosa no se hace distinción alguna respecto al destinatario, pues del mismo enunciado de la norma comunitaria se evidencia que el afectado puede ser un competidor, un consumidor, o incluso ambos (Unión Europea, 2005) ${ }^{10}$.

Elementos constitutivos del ilícito concurrencial. Todo mensaje publicitario que puede inducir a error a sus destinatarios ha de ser considerado como engañoso y, por ende, reprochable jurídicamente (López, 2004, p. 41). La incidencia de estos mensajes puede recaer directamente en los demás competidores, en los consumidores y/o usuarios o en ambos, teniendo siempre como consecuencia la alteración irregular de la competencia. De lo anterior, se desprenden los tres elementos que distinguen la publicidad engañosa:

- Una comunicación publicitaria que induce a error o puede inducir a error a las personas a las que se dirige $o$ afecta,

- Que afecte o pueda afectar el comportamiento económico de un consumidor o usuario, y/o,

- Que perjudique o tenga capacidad para perjudicar a un competidor

10 Al respecto el legislador comunitario ha manifestado, en el considerando 6, que la Directiva "No comprende ni atañe a las leyes nacionales sobre prácticas comerciales desleales que perjudican sólo a los intereses económicos de los competidores o que se refieren a transacciones entre comerciantes; para tener en cuenta el principio de subsidiariedad, los Estados miembros seguirán teniendo la capacidad de regular esas prácticas, de conformidad con el Derecho" (Unión Europea, 2005). 
Los elementos constitutivos antes mencionados están presentes en las dos modalidades de engaño acogidas por el texto de las normas antes citadas, que son:

i) Publicidad engañosa por acción. Esta clase de publicidad responde a la necesaria sumisión que la comunicación publicitaria debe mantener al principio de veracidad, según el cual, todas las afirmaciones ofrecidas en el mismo deben estar apegadas a la realidad. Esta sumisión conlleva una dificultad para el anunciante, dado el necesario ánimo de persuasión que contienen todos los mensajes publicitarios, quien deberá adecuar su contenido de tal manera que no dé cabida al planteamiento de un error (Desantes, Bell, Correidora y Alfonso, Cousido, \& Sanz, 1994, p. 116).

Para que una publicidad sea engañosa debe causar un error efectivo o tener vocación para producirlo. Por tanto, el reproche no dependerá de la materialización del error, sino de su aptitud para inducirlo; en consecuencia, debe analizarse si el anuncio sub examine, atendiendo a las circunstancias que lo rodean, tiene dicha vocación engañosa, lo cual conlleva la necesidad de examinar el anuncio publicitario en su integridad, bajo la óptica del consumidor medio del grupo relevante al que se dirige, para así poder establecer si, al ser interpretado, su contenido corresponde con la realidad, y si carece de aptitud para causar error.

ii) Publicidad engañosa por omisión. El reproche por publicidad engañosa también se configura cuando en la comunicación publicitaria se omite información que se debe poner en conocimiento del destinatario por ser relevante en la decisión de adquisición, al punto que, si la hubiera conocido, su conclusión hubiera sido diferente. También se considera engaño por omisión aquel derivado de un mensaje publicitario en el que se utilizan expresiones que siendo verdaderas, en el contexto usado implican una conclusión falsa, bien porque se emplean expresiones ambiguas y con significados diferentes, o bien porque son desconocidas para el destinatario (Newman, 2010, p. 6).

Considerando lo anterior, no puede entenderse que esta prohibición imponga al comerciante un deber general que le exija incluir en el mensaje toda la información sustancial sobre el bien o servicio; lo que en realidad se persigue es precisamente que los datos suministrados en la comunicación publicitaria sean causa de falsas expectativas en el consumidor (Fernández et al., 2010, p. 123).

\section{Factores que contribuyen a la deter- minación del engaño. El artículo 3 de la} Directiva 2006/114/CE ofrece un catálogo de factores que han de tenerse en cuenta para determinar si el anuncio se constituye como publicidad engañosa (Unión Europea, 2006). En primer lugar, se debe acudir a las características que rodean los bienes o servicios ofrecidos, tales como su disponibilidad, su naturaleza, su ejecución, su composición, el procedimiento y la fecha de fabricación o de prestación, su carácter apropiado, sus usos, su cantidad, sus especificaciones, su origen geográfico 
o comercial o los resultados que pueden esperarse de su utilización, o los resultados y las características esenciales de las pruebas o controles efectuados sobre los bienes o los servicios.

También ha de evaluarse el precio o su modo de fijación y las condiciones de suministro de bienes o de prestación de servicios, así como la naturaleza, las características y los derechos del anunciante, tales como su identidad y su patrimonio, sus cualificaciones y sus derechos de propiedad industrial, comercial o intelectual, o los premios que haya recibido o sus distinciones (De la Cuesta, 2002, p. 155).

Cuando, al aplicar estos criterios, el resultado de dicho análisis permite inferir que hubo engaño o un error, la comunicación publicitaria deberá ser clasificada como ilícita, pues de lo contrario causará una distorsión de la competencia al motivar una decisión de adquisición de un bien o servicio con base en una consideración que no es cierta.

\section{Actitud para incidir en el compor- tamiento del consumidor. El tipo} normativo que fundamenta el reproche de la publicidad por engañosa exige que la comunicación publicitaria disminuya la capacidad y el discernimiento del consumidor, haciendo que este tome una decisión económica, que de otra manera no hubiera escogido (Newman, 2010, p. 36). El legislador español ha precisado que deberá entenderse por comportamiento económico del consumidor aquellas decisiones para actuar o abstenerse de hacerlo con relación a la selección de una oferta o un oferente, la contratación de un bien o servicio y la forma de pago del precio (España, 1991).

En esta consideración, tal y como ocurre con la configuración del error, no se exige que la incidencia sobre el comportamiento sea efectiva, pues es suficiente con la simple aptitud para distorsionar, vista siempre desde la perspectiva del consumidor medio (Fernández et al., 2010, p. 116). La suficiencia exigida en la distorsión del comportamiento económico debe atender a la regla del minimis, y, por tanto, se podrán excluir de reprochabilidad aquellos anuncios que, pudiendo causar un error, no poseen incidencia alguna en su comportamiento económico o esta resulta insignificante.

Al respecto, puede considerar que el considerando 6 de la Directiva comunitaria es la puerta de entrada de esta regla, en el que se hace referencia a "las consecuencias de dichas prácticas comerciales desleales cuando estas son sustanciales", con lo que parecería excluirse las afectaciones insignificantes (Fernández et al., p. 2010, 116).

\subsection{La publicidad agresiva}

El artículo 16 de la Directiva 2005/29/ CE establece una prohibición general de prácticas comerciales desleales que distorsionan el comportamiento económico de los consumidores, que abarcan dos modalidades: las prácticas comerciales engañosas y las prácticas comerciales agresivas, estas últimas, como novedad legislativa en el ámbito europeo. Corola- 
rio de esto son los considerandos de la citada Directiva, en los que el legislador manifiesta que la tipificación de las prácticas comerciales agresivas tiene como propósito erradicar toda posibilidad de afectación o merma significativa sobre la libertad de elección del consumidor (Unión Europea, 2005).

Concepto. En su propósito, el legislador comunitario puntualizó el concepto de prácticas agresivas en el artículo 16 de la Directiva 2005/29/CE, considerando como tal:

Toda práctica comercial que, en su contexto fáctico, teniendo en cuenta todas sus características y circunstancias, merme o pueda mermar de forma importante, mediante el acoso, la coacción, incluido el uso de la fuerza, o la influencia indebida, la libertad de elección o conducta del consumidor medio con respecto al producto y, por consiguiente, le haga o pueda hacerle tomar una decisión sobre una transacción que de otra forma no hubiera tomado (Unión Europea, 2005).

El legislador español, al transponer la Directiva 2005/29/CE al ordenamiento interno, en el artículo 18.1 de la LCD, acoge la definición dada por la norma comunitaria, a la cual le adiciona un inciso para aclarar que la influencia indebida ha de ser entendida como la utilización de una posición de poder en relación con el destinatario de la práctica para ejercer presión, incluso sin usar fuerza física ni amenazar con su uso (España, 2009).
La definición de práctica agresiva abarca, incluso, la publicidad comercial. Si bien es cierto que los mensajes publicitarios están generalmente dirigidos a una masa de consumidores en donde el anunciante no entra en contacto directo con el destinatario, existen ocasiones en las que se acude a la publicidad directa para informar sobre productos y servicios con el ánimo de persuadir su adquisición (Fernández et al., 2010, p. 182). Al acudir a esta vertiente publicitaria el anunciante establece una interacción directa con un consumidor individualizado, empleando como medios de difusión aquellos que permiten dicho contacto, como las visitas al domicilio, el teléfono, el fax, el e-mail, los mensajes de texto y similares, pudiendo con su conducta incurrir en prácticas tipificadas como agresivas frente al consumidor.

Es pertinente tener en cuenta que, como ya se ha mencionado, la Directiva 2005/29/CE en su aplicación solo abarca las prácticas comerciales que tengan lugar en las relaciones entre empresarios con consumidores. Las prácticas agresivas tipificadas en su contenido no escapan a dicha restricción. Sin embargo, esto no ocurre así en el derecho español, en cuya ley de transposición el legislador ha acomodado el ámbito objetivo de aplicación a cualquier conducta realizada en el mercado con finalidad concurrencial, incluidas las relaciones entre empresarios y profesionales (España, 2009)" en las que su incidencia puede ser mínima o

"El legislador español acoge la posibilidad que ofrece la Directiva 2005/29/CE en el Considerando 6, para regular estas prácticas, en virtud del principio de subsidiaridad. 
inexistente, aunque posible (Massaguer, 2010, p. 21).

Sin perjuicio de lo anterior, el fundamento jurídico para su calificación como práctica agresiva sí que variará dependiendo del sujeto pasivo. En aquellos casos en que el afectado sea un competidor se debe acudir al artículo 8 LCD, mientras que si la víctima es un consumidor, el encuadre jurídico dependerá del catálogo de prácticas agresivas contenido en los artículos 28 a 31 LCD (Fernández et al., 2010, p. 189)

Elementos constitutivos del ilícito concurrencial. La Directiva 2005/29/ CE establece unos criterios a tener en cuenta para calificar como agresiva una práctica comercial, que, como es lógico, resulta aplicable a la publicidad comercial. Estos criterios están contenidos en el artículo 9 de la LCD, y se agrupan en tres segmentos:

- El momento, el lugar, la naturaleza o la persistencia de producción del agravio. Este criterio resulta fácilmente aplicable cuando la publicidad se ha efectuado mediante visitas al domicilio o en lugares públicos, pero no lo es tanto si en su difusión se han empleado nuevas tecnologías.

- El uso de un lenguaje o un comportamiento amenazador o insultante. Este criterio puede llegar a no ser tan evidente cuando se trata de publicidad agresiva, pues el anunciante evitará en lo posible utilizar palabras obscenas o amenazantes, para reemplazarlas por un lenguaje amable y persuasivo.
- La explotación por parte del comerciante de cualquier infortunio o circunstancia específicos, lo suficientemente graves como para mermar la capacidad de discernimiento del consumidor, de los que el comerciante tenga conocimiento, para influir en la decisión del consumidor con respecto al producto (Lieñeda $\mathcal{E}$ Irákulis, 2007, p. 161).

\subsection{Publicidad desleal propiamente dicha como práctica comercial desleal}

Las modalidades concretas que dan lugar a la publicidad desleal propiamente dicha no han sido especificadas por las directivas comunitarias ni por la LGP; sin embargo, se ha entendido que el concepto engloba vertientes publicitarias que incorporan en sus mensajes actos de confusión, de denigración, de comparación, de aprovechamiento ilícito injustificado de signos distintivos ajenos y contrarios a la buena fe o a las normas de corrección y buenos usos mercantiles (Lieñeda \& Irákulis, 2007, p. 151). Así las cosas, trataremos de encontrar un concepto de publicidad desleal para luego detenernos en la dificultad que surge de la no incorporación en el ámbito comunitario de la modalidad desleal de la publicidad.

Definición. Para el propósito que aquí nos ocupa, es decir, el de acercarnos a un concepto de publicidad desleal propiamente dicha, nos resulta útil la redacción del ya derogado artículo 10 del EP, según el cual: "Se considera desleal la actividad publicitaria dirigida a provocar confusión entre bienes y servicios, la que tiene a 
producir el descrédito de los competidores o de los productos de los mismos y, genéricamente, la contraria a las normas de corrección y buenos usos mercantiles" (España, 1964).

En un sentido similar al derogado artículo, encontramos a Descalzo quien define la publicidad desleal a partir de dos supuestos: la actividad publicitaria dirigida a provocar confusión entre bienes y servicios, y la dirigida a desacreditar a los competidores o sus productos (Descalzo, 2003, p. 47). Esta definición, aunque acertada, no es suficiente para englobar algunas de las modalidades abarcadas por la publicidad desleal.

A su vez, Rozados Oliva considera que la publicidad desleal es un supuesto de publicidad ilícita en cuya realización contravienen los principios y reglas que imperan en un sistema de competencia desleal (Rozados, 2009, p. 74). Esta definición, a la postre, resulta más acertada que la anterior, pero su amplitud puede conllevar a equívocos, pues es claro que las vertientes publicitarias engañosas y agresivas también transgreden dichos principios.

No obstante, si agrupamos las dos posturas doctrinales, que para nada resultan excluyentes, podríamos encontrar un concepto adecuado atribuible a la publicidad desleal, en el que estarían recogidos todos los supuestos que se considera que forman parte de esta modalidad promocional.

\section{La ausencia de la publicidad desleal}

Revista Opinión Jurídica Universidad de Medellín en el derecho comunitario. Como se mencionó en líneas anteriores, en el derecho comunitario no existen referencias directas sobre la publicidad desleal; sin embargo, al examinar con detenimiento el contenido de las Directivas 2005/29/CE y 2006/114/CE, se reconocen tipos normativos que regulan figuras pertenecientes a esta especie publicitaria, cuya reprochabilidad se fundamenta bajo matices de engaño o agresividad, como ocurre con la publicidad comparativa ilícita, entre otras.

Esta situación no es pacífica en la doctrina española, en donde la LGP mantiene la categoría de publicidad desleal, sin más, y remite a la LCD para que allí se busque cuáles son las conductas condenables bajo esta figura (Broseta \& Martínez, 2010, p. 207) ${ }^{12}$. Autores como Fernández Carballo-Calero, Herrera Petrus y Tato Plaza (2010, p. 294) identifican como publicidad desleal propiamente dicha algunos tipos normativos que fueron incorporados a la LCD por el acto de transposición de la Directiva europea (Ley 29/2009 de España), clasificados por esta última como supuestos de publicidad engañosa o agresiva.

12 Al respecto, el autor expone que "es necesario poner de relieve una cierta contradicción que se aprecia entre ambas normas. De una parte, el articulo 3 LGP (publicidad ilícita), contiene una tipificación de lo que se entiende por publicidad ilícita, categoría dentro de la cual se incluye, entre otras, la publicidad engañosa, la desleal y la agresiva. La misma tendrá la consideración de actos de competencia desleal en los términos contemplados en la LCD. A su vez, esta última Ley, en su artículo 18 señala la publicidad considerada ilícita en la LGP, se reputara desleal. Ello hace surgir la duda de si toda publicidad ilícita es, al mismo tiempo desleal o si tan sólo la publicidad ilícita contemplada en la letra e) del artículo 3 LGP es desleal" (Broseta E Martínez, 2010, p. 207). 
Así entonces, podríamos afirmar que en el ámbito europeo no es admisible del todo el concepto de publicidad desleal propiamente dicho, como sí ocurre en el derecho español, en razón a que los supuestos de publicidad desleal se atribuyen a otras modalidades publicitarias reprochables (Broseta \& Martínez, 2010, p. 198). Sin embargo, a modo de interpretación del legislador español, podría justificarse el tratamiento diferenciado entre publicidad engañosa y desleal, si se considera, "que estamos ante distintos bienes jurídicos protegidos, de suerte que en el segundo de los casos el centro de atención se encuentra en los Derechos de los competidores y, por tanto, en la protección de la competencia misma" (Rozados, 2009, p. 75), mientras que el primero, como ya se ha dicho, propende por el derecho de los consumidores. Esta "interpretación" del querer del legislador podría no ser suficiente si tenemos en cuenta que la mejor protección para un consumidor es el poder garantizarles el correcto funcionamiento de la competencia en el mercado.

\section{CONCLUSIONES}

El legislador comunitario ha elaborado un verdadero régimen legal sobre la publicidad comercial. Para este propósito, se han tenido en cuenta las posibles afectaciones que el anuncio puede causar sobre los demás empresarios que concurren en el mercado, y/o sobre los consumidores y usuarios a los que está dirigida. Las disposiciones sobre esta materia están contenidas en dos directivas, la Directiva
2005/29/CE, cuyo ámbito de aplicación se restringe a las prácticas desleales de las empresas que afectan los intereses económicos de los consumidores, y la Directiva 2006/114/CE, cuyo objeto principal es la regulación de la publicidad engañosa y la publicidad comparativa, cuya aplicación está enfocada, con preferencia, a los competidores.

El objeto de la regulación publicitaria es la protección del mercado, excluyendo la posibilidad de acudir a las prácticas comerciales desleales para lograr un beneficio ilícito a quienes las promuevan en detrimento del interés general, representado en el bienestar de los demás competidores y de los consumidores o usuarios, quienes son los verdaderos protagonistas concurrenciales.

El establecimiento, en el nivel comunitario, del régimen publicitario conlleva su necesaria transposición al ordenamiento interno de cada Estado miembro. Para dar cumplimiento a esta exigencia, España profiere la Ley 29/2009, con la cual modifica el régimen vigente sobre competencia desleal, y algunos aspectos sobre publicidad. Sin embargo, el legislador español fue más allá de lo exigido desde el ámbito comunitario, pues estableció tres modalidades de publicidad ilícita: la publicidad engañosa y la publicidad agresiva -presentes en el derecho comunitario-, y la publicidad desleal propiamente dicha, como modalidad residual, para acoger los demás supuestos reprochables que no encajen en las dos primeras. 
Dado que la reprochabilidad de la publicidad comercial obedece al engaño efectivo que pueda causar el anuncio, o a la vocación de este para desencadenarlo, las normas en materia de publicidad comercial permiten incorporar expresiones que, siendo ajenas a la realidad, carezcan de la aptitud para configurar el engaño, tal y como ocurre con la publicidad superlativa y el product placement.

Con lo anterior, se evidencia la importancia que el mensaje publicitario ha cobrado como instrumento de marketing de productos y servicios. Y como tal, el derecho se ha preocupado por establecer un régimen objetivo que garantice la debida lealtad que debe ser observada en el mercado por quienes allí intervienen. Para lograr este propósito, el legislador comunitario buscó unificar las reglas sobre dicha materia en el ámbito de la Unión, garantizando unos mínimos establecidos por las directivas proferidas a tal fin, y que Estados miembros, como España, han acogido para asegurar los intereses de los intervinientes en las relaciones de mercado.

\section{BIBLIOGRAFÍA}

Bacigalupo, M., Fuentetaja, J., E Linde, E. (2012). Principios de derecho de la Unión Europea (5 Ed.). Majadahonda: Colex.

Benavides, J. (1997). Lenguaje publicitario. Hacia un estudio del lenguaje de los medios. Madrid: Síntesis

Broseta, M. E Martínez, F. (2010). Manual de derecho mercantil (17 Ed. Vol. 1). Madrid: Tecnos.
Comisión de la Unión Europea. (2001). Libro Verde sobre la protección de los consumidores en la UE. Recuperado de http://europa.eu/ legislation_summaries/other/132028. es.htm

De la Cuesta, J. M. (2002). Curso de derecho de la publicidad. Pamplona: Ediciones Universidad de Navarra, EUNSA.

Desantes, J., Bell, I., Correidora y Alfonso, L., Cousido, P., E Sanz, R. (1994). Derecho de la información II. Los mensajes informativos. Madrid: Colex.

Descalzo, A. (2003). Principio de veracidad y política pública en el mercado comercial. Madrid: Dikinsson.

España. (1964). Ley 61/1964, de 11 de junio, por la que se aprueba el Estatuto de la Publicidad. Esapña.

España. (1985). Acta de Adhesión de España a las Comunidades Europeas, rubricado el 12.06.1985 en el Salón de Columnas del Palacio Real de Madrid, para entrar en vigor el 1 de enero de 1986. España.

España. (1988). Ley 34/1988, de 11 de noviembre, General de Publicidad (Modificada por la Ley 29/2009, de 30 de diciembre). España.

España. (1991). Ley 3/1991, de 10 de enero, de Competencia Desleal. España.

España. (2002). Ley 39/2002, de 28 de octubre, de transposición al ordenamiento jurídico español de diversas directivas relativas a la protección de los intereses de los consumidores y usuarios. España.

España. (2007). Ley 15/2007, de 3 de julio, de Defensa de la Competencia. España.

España. (2009). Ley 29/2009, de 30 de diciembre, por la que se modifica el régimen legal de la competencia desleal y de la publicidad para la mejora de la protección de los consumidores y usuarios. España. 
Fernández, P., Herrera, C., E Tato, A. (2010). La reforma de la ley de competencia desleal (1 Ed.). Las Rozas-Madrid: La Ley.

Higueras, I. (1998). Comunicaciones comerciales en España diez años después de la Ley General de la Publicidad. Communication $\mathcal{E}$ Society, Volumen 11, (Número 1), pp. 143-172.

Lara, R. (2011). El ilícito concurrencial por denigración tras la reforma del régimen legal de la competencia desleal y de la publicidad. Aranzadi civil-mercantil, Volumen 1, (Número 3, junio), pp. 47-80.

Lieñeda, E. E Irákulis, N. (2007). La publicidad ilicita y el estudio de la Directiva 2005/29/ CE sobre prácticas comerciales desleales. Aranzadi civil: Revista quincenal, (Número 2), pp. 2433-2463.

López, M. (2004). La publicidad y el derecho a la información en el comercio electrónico. Eumed. Accesible a texto completo en: html://http:// www.eumed.net/cursecon/libreria.

Massaguer, J. (2010). Las prácticas agresivas como acto de competencia desleal. Actualidad Jurídica Uría Menéndez, (Número 27), pp.17-32.

Menéndez, A., E Rojo, Á. (2013). Lecciones de derecho mercantil (11 Ed.). Madrid: Thomson Reuter.

Newman, S. (2010). La protección de los competidores en Europa: comentario a la Directiva 2006/114/CE sobre publicidad engañosa y publicidad comparativa. Revista General de Derecho Europeo, (Número 22, noviembre), disponible en: http://www. iustel.com/v2/revistas/detalle _ revista. asp?id $=13$ Enumero $=22$

Peña, G. (2007). Elementos contextuales en el discurso publicitario. Círculo de Lingüística Aplicada a la Comunicación (clac), (Número 31), pp 34-51.

Pérez, P. A. (1990). La información en la contratación privada : en torno al deber de informar en la Ley general para la defensa de los consumidores y usuarios (1 Ed.). Madrid: Instituto Nacional del Consumo.

Real Academia Española. (2001). Diccionario de la Lengua Española. 21. Retrieved 10.08.2014

Rodríguez, J. (1999). Derecho de la Comunicación. Santiago de Compostela: Laverde.

Rozadas, M. J. (2009). Derecho administrativo de la publicidad (Vol. 1). Valencia: Tirant lo Blanch.

Santaella, M. (1989). El nuevo derecho de la publicidad. Madrid: Civitas.

Santaella, M. (2003). Derecho de la publicidad. Madrid: Civitas.

Souvirón, J. M. (1999). Derecho público de los medios audiovisuales: radiodifusión y televisión (Vol. 1). Granada: Comares.

Tato, A. (2010). La reforma de la ley general de publicidad. Revista de Derecho de la Competencia y la Distribución, (Número 7), pp. 141-154

Tribunal Constitucional de España. (1989). Sentencia del 26 de enero de 1989, RTC 1989/15 (1989).

Unión Europea. (1984). Directiva 84/450/CEE del Consejo, de 10 de septiembre de 1984, relativa a la aproximación de las disposiciones legales, reglamentarias y administrativas de los Estados Miembros en materia de publicidad engañosa. Unión Europea.

Unión Europea. (1997). Directiva 97/55/CE del Parlamento Europeo y del Consejo, de 6 de octubre de 1997, por la que se modifica la Directiva 84/450/ CEE sobre publicidad engañosa. Unión Europea.

Unión Europea. (2005). Directiva 2005/29/CE del Parlamento Europeo y del Consejo, de 11.05.2005, relativa a las prácticas comerciales desleales de las empresas en sus relaciones con los consumidores en el mercado interior, que modifica las Directivas 84/450/CEE, 97/7/CE, 98/27/CE y 2002/65/CE, 
y el Reglamento (CE) $n . .^{\circ}$ 2006/2004 (Directiva sobre las prácticas comerciales desleales). Unión Europea.

Unión Europea. (2006). Directiva 2006/114/CE, de 12 de diciembre de 2006, del Parlamento Europeo y del Consejo, sobre publicidad engañosa y publicidad comparativa. Unión Europea.
TJUE. (2011). Sentencia del 12 de mayo de 2011. Konsumentombudsmannen contra Ving Sverige AB. Petición de decisión prejudicial: Marknadsdomstolen - Suecia. Asunto C-122/10. TJUE.

Vilajoana, S. (2011). Las Leyes de la publicidad: Límites jurídicos de la actividad publicitaria. Barcelona: Editorial UOC. 